\title{
Group Hibernation Does Not Reduce Energetic Costs of Young Yellow-Bellied Marmots
}

\author{
Kenneth B. Armitage ${ }^{\star}$ \\ Brett C. Woods ${ }^{\dagger}$ \\ Department of Ecology and Evolutionary Biology, University \\ of Kansas, Lawrence, Kansas 66045-7534
}

Accepted 4/21/03

\begin{abstract}
We investigated mechanisms of energy conservation during hibernation. The amount of time torpid was significantly less for groups of three young marmots than for marmots hibernating singly. Mean daily mass loss (DML; as $\mathrm{mg} \mathrm{d}^{-1} \mathrm{~g}^{-1}$ immergence mass) averaged 1.33 for single marmots and 1.46 for grouped young. Animals were active $17.3 \%$ of the time, which used $82.4 \%$ of the energy, and were torpid $82.7 \%$ of the time, which used $17.6 \%$ of the energy expenditure. During longer torpor bouts, more time was spent in deep torpor, which decreased the hourly cost of a complete bout. Bout oxygen consumption $\dot{\mathrm{V}}_{\mathrm{O}_{2}}$, percent time in deep torpor, and body temperature $\left(T_{\mathrm{B}}\right)$ during deep torpor changed seasonally and were curvilinearly related to when in the hibernation period the measurements were made and probably represent a stage in the circannual metabolic cycle. The decrease of environmental temperature $\left(T_{\mathrm{E}}\right)$ to $2^{\circ} \mathrm{C}$ significantly increased metabolism. Potential costs of low $T_{\mathrm{E}}$ were reduced by allowing $T_{\mathrm{B}}$ to decrease, thereby reducing the $T_{\mathrm{B}}$ to $T_{\mathrm{E}}$ gradient. Average monthly metabolic rate was high early and late in the hibernation period when time spent euthermic was greater and when $\dot{\mathrm{V}}_{2}$ was higher. Over the hibernation period, energy saved averaged $77.1 \%$ and $88.0 \%$ of the costs for winter and summer euthermic metabolism, respectively. Hibernation costs were reduced by the seasonal changes, the high percentage of time in torpor, the rapid decline in $\dot{\mathrm{V}}_{2}$ following arousal, and allowing $T_{\mathrm{B}}$ to decline at lower $T_{\mathrm{E}}$. Asynchrony in the torpor cycles increased energy expenditures in group hibernators, which negated possible beneficial effects of group hibernation.
\end{abstract}

\footnotetext{
*Corresponding author; e-mail: marmots@ukans.edu.

${ }^{\dagger}$ Present address: Department of Biology, Beloit College, 700 College Street, Beloit, Wisconsin 53511.
}

Physiological and Biochemical Zoology 76(6):888-898. 2003. (c) 2003 by The University of Chicago. All rights reserved. 1522-2152/2003/7606-2050\$15.00

\section{Introduction}

Hibernation is a mechanism for conserving energy during a season of food shortage. Most studies focused on physiological changes during hibernation, such as decreased heart rate, body temperature, and metabolic rate during a torpor bout (Lyman et al. 1982); few analyzed the mechanisms of energy conservation, and the young were generally overlooked. All species of marmots accumulate fat as the sole source of energy during hibernation. The stored fat must be sufficient to provide energy for maintenance metabolism during torpor bouts in the thermoneutral zone, energy for coping with low-temperature stress (Arnold et al. 1991; Ortmann and Heldmaier 1992; Armitage et al. 2000), energy for initiating reproduction, and energy for after emergence until food becomes available (Armitage 1999).

Prolonged exposure of marmots to low ambient temperature may result in mortality (Arnold 1990), and long winters decrease survival (Armitage and Downhower 1974; Arnold 1993; Schwartz and Armitage 2002), probably because animals exhaust their fat resources. Summer drought results in poor growth and reduced accumulation of fat and high mortality in the subsequent hibernation (Davis and Ludwig 1981; Armitage 1994). Clearly, fat is a critical resource; therefore, we would expect marmots to conserve fat by evolving mechanisms to reduce energy expenditures. Some of these mechanisms include the circannual rhythm of metabolism, which decreases energy use during euthermy about 30\% from the peak in summer to the low in winter (Ward and Armitage 1981); the annual molt, which decreases energy use about $37 \%$ in adults (Armitage and Salsbury 1993) and 35\% in young (Armitage and Salsbury 1992); and a resting metabolic rate that is much lower than that predicted from body size (Armitage and Salsbury 1992).

Different species of marmots apparently have different strategies for coping with the cold stress of hibernation (Armitage et al. 2000). Some species may be energetically more efficient, which is expressed by decreased mass loss during hibernation (Armitage et al. 2000), some species may rely on large fat stores made possible by large body size and the accumulation of fat greater than that predicted from body size (Armitage 1999), and other species may use social thermoregulation (Arnold 1993), which reduces metabolic costs as measured by oxygen consumption (Vasiliev 1992; Vasiliev and Solomonov 1996).

Previous studies of the solitary hibernators Marmota monax and Marmota flaviventris (Armitage et al. 2000, 2003) concluded that $M$. monax relies on relatively large size and a short hibernation season and that $M$. flaviventris is energetically ef- 
ficient. However, young yellow-bellied marmots (M. flaviventris) may hibernate socially (Lenihan and Van Vuren 1996); thus, there is a potential for possible benefits from group hibernation.

The purpose of this study was to describe the energetics of young yellow-bellied marmots and to explore for possible differences in the hibernation energetics of young marmots hibernating singly or in groups.

\section{Material and Methods}

\section{Animals and Housing}

Ten (five males, five females) young yellow-bellied marmots were livetrapped in the Upper East River Valley, Gunnison County, Colorado, in mid-August 1999. These young were taken from study sites where all marmots have been livetrapped yearly and their sex, mass, age, kinship, and reproductive status noted (Schwartz et al. 1998; Armitage 2002). The marmots, approximately 2 mo old, were transported to the University of Kansas, Lawrence, where they underwent a 2 -wk quarantine before a calibrated temperature-sensitive radio-transmitter (Mini-Mitter VM-FH-LT-DISC) was surgically implanted in the abdominal cavity of six of them. Four marmots were housed singly, and six were housed in two groups of three littermates each. One marmot from each group received a temperature transmitter. All animals were housed in standard rabbit cages placed in temperature-controlled, walk-in environmental rooms. The marmots were maintained at $15^{\circ} \pm 0.5^{\circ} \mathrm{C}$ at a $12 \mathrm{~L}: 12 \mathrm{D}$ photoperiod with Purina rodent diet and water provided ad lib. until all individuals gained mass and completed molting. Three individuals lost mass until they were treated with a vermifuge and passed ascarid worms; thereafter, they gained mass. By October 8, there was a noticeable decrease in eating and drinking. At that time, we provided each cage with a wire-mesh nest-box and paper towels, removed food, decreased room temperature to $6^{\circ} \pm 0.5^{\circ} \mathrm{C}$, and turned off all lights. Animals were fed when hibernation terminated. Each animal was permitted to take up to three to five towels each torpor bout; their accumulation was limited by the size of the nest-box.

Torpor was monitored in the environmental (=hibernation) rooms by entering the room and using red light to record the body temperature $\left(T_{\mathrm{B}}\right)$ of the six animals once daily and noting when paper towels were taken into the nest-boxes. An animal was considered torpid when its $T_{\mathrm{B}}$ was lower than $30^{\circ} \mathrm{C}$ (Heldmaier et al. 1993). Because a marmot could possibly arouse shortly after $T_{\mathrm{B}}$ was recorded and descend into torpor before the next recording was made, we used the disappearance of paper towels as an indicator of arousal as a check against the $T_{\mathrm{B}}$ records. In addition, $T_{\mathrm{B}}$ was recorded every $5 \mathrm{~min}$ (see following section for temperature-recording methods) for each animal at least once through a complete torpor bout, that is, from the onset of torpor through arousal to the next onset of torpor. Daily recordings were used to calculate bout lengths and amount of time torpid. Differences in time spent torpid among months and between single and group hibernators were tested with repeated-measures ANOVA.

\section{Bout Measurements: $\dot{V}_{2}$ and $\mathrm{T}_{B}$}

For each marmot or group of three, oxygen consumption $\left(\dot{\mathrm{V}}_{2}\right.$, as oxygen consumption per hour) and $T_{\mathrm{B}}$ were recorded for one complete bout and for an additional complete bout for the two groups of three and for two of the singles before all animals terminated hibernation. The nest-box with the marmot was placed in a Plexiglas chamber that in turn was placed in an environmental growth chamber and connected to an airflow system such that air was drawn through the sealed metabolism chamber at the rate of $590 \mathrm{~mL} \mathrm{~min}{ }^{-1}$. We used the lowest flow rate that provided oxygen consumption values that could be consistently detected from ambient because experiments with Marmota monax demonstrated that increasing flow rates at low environmental temperature $\left(T_{\mathrm{E}}\right)$ increased $\dot{\mathrm{V}}_{2}$ (Armitage et al. 2000), and low flow rates would more closely approximate the conditions of natural hibernacula. Flow rate was measured with a calibrated glass flow meter. Temperature was measured continuously in the metabolism chamber and outside the nest-box and was maintained at $6^{\circ} \pm 0.1^{\circ} \mathrm{C}$ except for two bouts measured at $2^{\circ} \pm 0.1^{\circ} \mathrm{C} . T_{\mathrm{B}}$ signals were detected with a Mini-Mitter RA-1010 receiver, and oxygen concentrations were measured with an electrochemical oxygen analyzer (Ametek Model S-3A1) after the air was passed through indicator Drierite to remove water. The analyzer was referenced at least once daily and hourly when problems with drift occurred. Output signals from the radio receiver and oxygen analyzer were input every $5 \mathrm{~min}$ into a Data Quest III data analysis system. All $\dot{\mathrm{V}}_{2}$ values were converted to standard pressure. Hourly means were calculated from the recorded data. Additional details of the measurement system are described elsewhere (Armitage and Salsbury 1992).

Each torpor bout was divided into three phases (Fig. 1): arousal (rapid increase in $\dot{\mathrm{V}}_{2}$ and $T_{\mathrm{B}}$ ), euthermy $\left(T_{\mathrm{B}}>30^{\circ} \mathrm{C}\right.$ ), and torpor $\left(T_{\mathrm{B}}<30^{\circ} \mathrm{C}\right.$, except during arousal $)$. We also defined deep torpor as the time when $\dot{\mathrm{V}}_{2}$ was at low, stable values (Fig. 1). Because a stable $T_{\mathrm{B}}$ occurred only during deep torpor, only during deep torpor could $T_{\mathrm{B}}$ and $\dot{\mathrm{V}}_{2}$ be compared among individuals and among different $T_{\mathrm{E}}$ 's. Because $\dot{\mathrm{V}}_{2}$ decreased to low, stable values much more rapidly than $\operatorname{did} T_{\mathrm{B}}$ (Armitage et al. 2000; Woods 2001; Woods et al. 2002), $\dot{\mathrm{V}}_{\mathrm{O}_{2}}$ was considered a more reliable indicator of deep torpor than $T_{\mathrm{B}}$. The hourly means were used to calculate the total oxygen consumption for each phase of the torpor bout, and the sum of the oxygen consumption for the three phases provided the total oxygen consumption for the entire torpor bout. The sum for each phase 


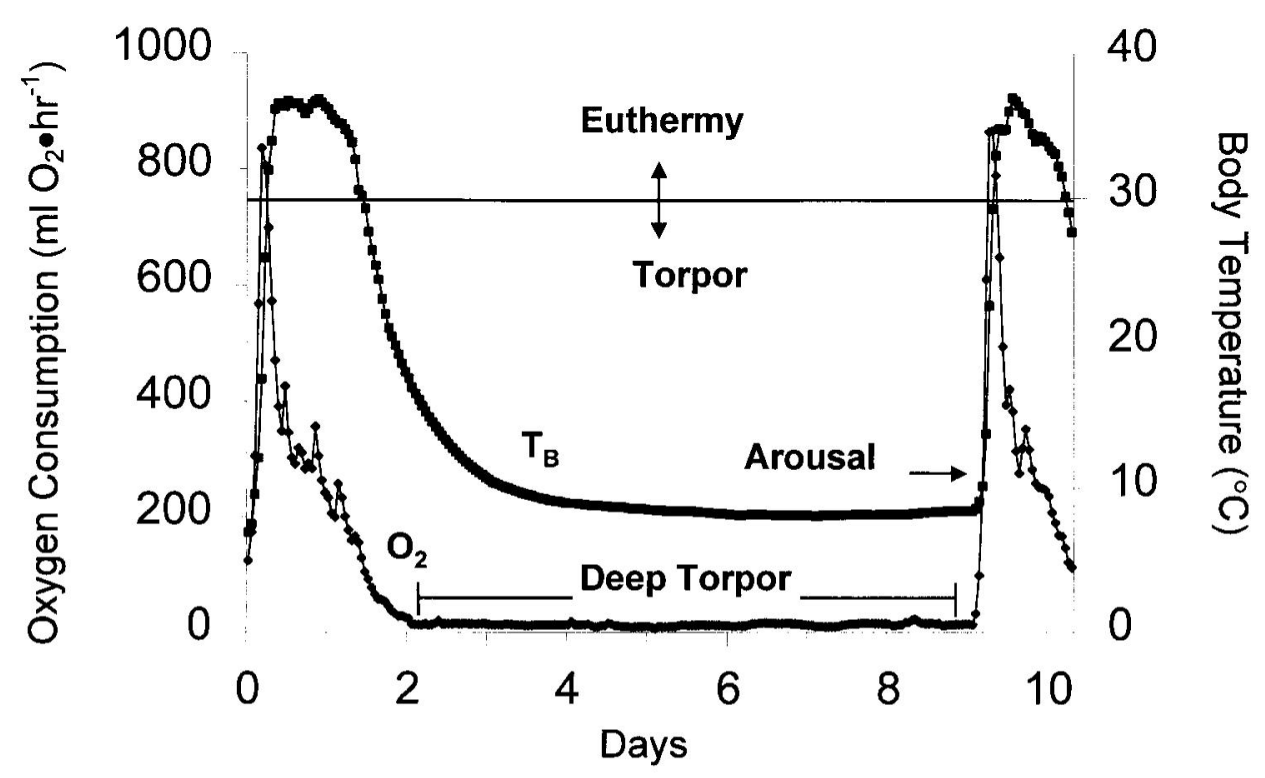

Figure 1. Body temperature and oxygen consumption during a complete torpor bout for a young marmot at $6^{\circ} \mathrm{C}$. Marmots were considered torpid when $T_{\mathrm{B}}$ was $<30^{\circ} \mathrm{C}$; deep torpor occurred when $\dot{V}_{\mathrm{O}_{2}}$ was at low, stable values.

and for the entire bout was divided by the number of hours spent in that phase or in the complete bout to provide a mean $\dot{\mathrm{V}}_{2}$ as oxygen consumption per hour. This mean was divided by the body mass to produce a mass-specific $\dot{\mathrm{V}}_{2}$. We also calculated the percentage of time spent and the percentage of bout $\dot{\mathrm{V}}_{2}$ expended in each of the three phases of the bout and in deep torpor. To correct for the influence of seasonal changes in metabolism, a quadratic regression line was fitted to the mean values of bout $\dot{\mathrm{V}}_{2}$ and $T_{\mathrm{B}}$ from all 10 measured bouts as a function of when in the hibernation period the measurement was made. To determine what factors potentially most influenced $\dot{\mathrm{V}}_{2}$, Spearman's rank correlation coefficient was used to correlate $\dot{\mathrm{V}}_{2}$ with body mass, $T_{\mathrm{B}}$, and bout length. During metabolic measurements, body mass over the hibernation period ranged from 950 to $2,285 \mathrm{~g}$ for animals housed singly and from 2,375 to $4,950 \mathrm{~g}$ (combined for all individuals) for groups of three. Differences in mass loss between single and group hibernators were tested with the Mann-Whitney test, a better statistical test when sample size in each group is small (Sokal and Rohlf 1981). Where appropriate, results are presented as the mean $\pm 1 \mathrm{SD}$.

\section{Temperature Effects}

$\dot{\mathrm{V}}_{2}$ and $T_{\mathrm{B}}$ were measured and conductance was calculated during deep torpor at $4^{\circ} \mathrm{C}$ and $2^{\circ} \mathrm{C}$ for three single marmots and the two groups of three. These measurements were made immediately following the measurement of a complete torpor bout so that the measurements were made at the same time in the seasonal cycle. The effects of $T_{\mathrm{E}}$ on $T_{\mathrm{B}}, \dot{\mathrm{V}}_{2}$, and conductance were tested by one-way ANOVA.

\section{Energy Budget}

An energy budget was calculated for each marmot for each 30d period during hibernation. Animals were standardized to the first day of torpor rather than to calendar month. If an animal terminated hibernation, its energy budget was calculated only for that part of the time period before termination. Because bout metabolism (Fig. 3) changed seasonally, we had to calculate curves for active $\dot{\mathrm{V}}_{2}$ (euthermy + arousal) and torpid $\dot{\mathrm{V}}_{2}$. We used measured values of active and torpid $\dot{\mathrm{V}}_{2}$ to produce curvilinear regressions $(X=$ time since immergence): active $\dot{\mathrm{V}}_{2}\left(\mathrm{~mL} \mathrm{~h}{ }^{-1}\right)=0.2031-0.00163 X+0.00000827 X^{2}$, $P=0.02, \quad R^{2}=0.62 ;$ torpid $\dot{V}_{\mathrm{O}_{2}}\left(\mathrm{~mL} \quad \mathrm{~h}^{-1}\right)=0.0135-$ $0.000113 X+0.00000045 X^{2}, P=0.01, R^{2}=0.74$. These regression curves were used to calculate mass-specific $\dot{V}_{O_{2}}$ values for each of the 30-d periods. We used mean body mass of all young and compensated for mass loss during hibernation by deducting $75.3 \mathrm{~g}$ ( $30 \mathrm{~d} \times 2.51 \mathrm{~g}$, mean loss per day) each $30 \mathrm{~d}$ from the mean mass of the previous time period. These values were used to calculate average daily metabolic rate (ADMR) from the following equation: $\mathrm{ADMR}=$ active $\dot{\mathrm{V}}_{2} \times$ number of hours active + torpid $\dot{\mathrm{V}}_{2} \times$ number of hours torpid. ADMR was multiplied by 30 to produce the average monthly metabolic rate $\left(A M M R\right.$ in liters $[\mathrm{L}]$ of $\mathrm{O}_{2}$ ). 


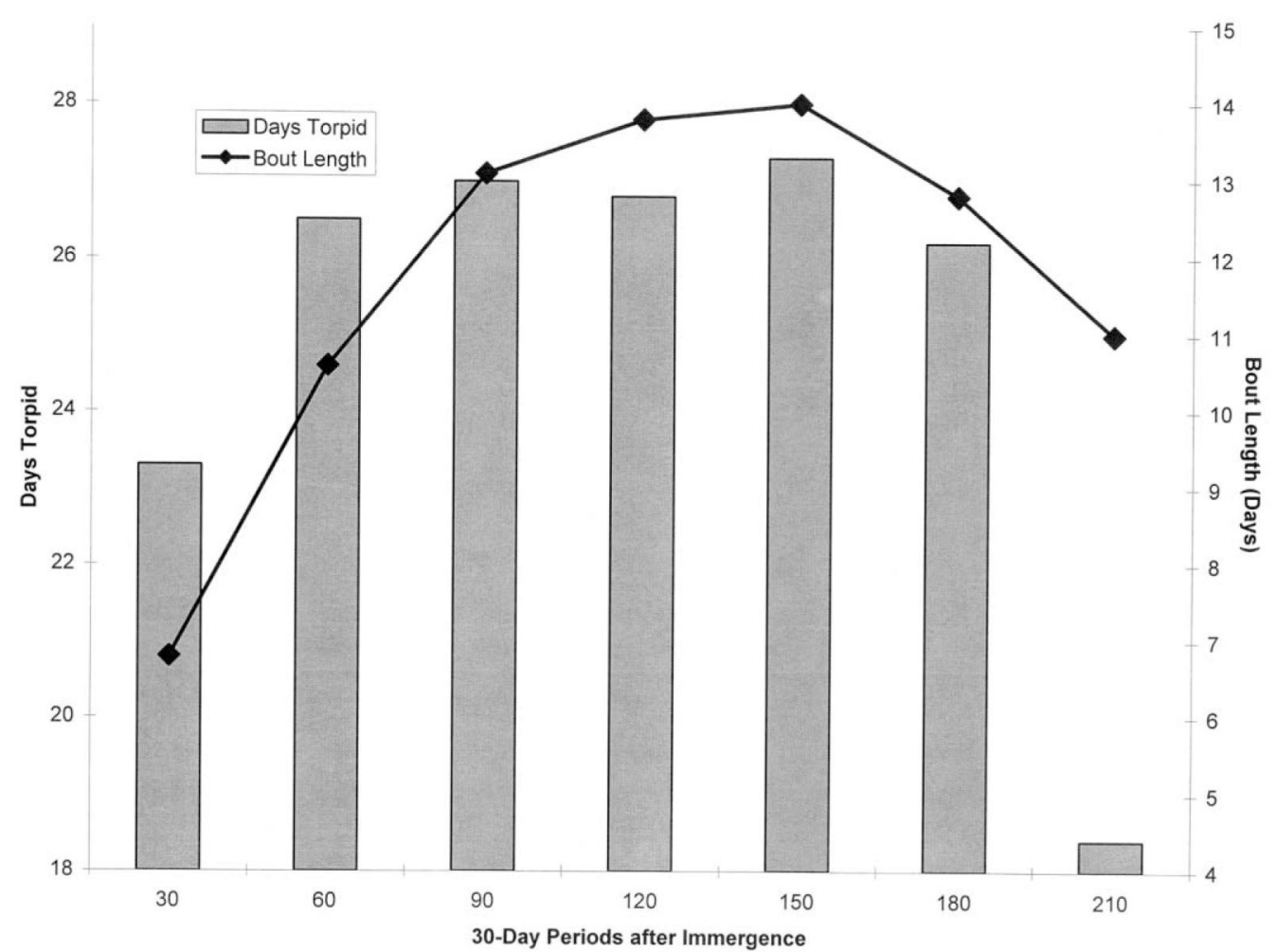

Figure 2. Number of days torpid and bout length in each 30-d period during hibernation. Bout length is the moving average for the mean of 10 young (except seven young in period 210). All values were standardized to the first day of immergence.

\section{Results}

\section{Hibernation Period and Torpor Bouts}

The first marmots hibernated on October 12, and the last animals (a group of three) hibernated on December 1. The length of the hibernation period (the time between the first torpor and the last arousal) averaged $204.2 \pm 23.1 \mathrm{~d}$. Because of the variation in hibernation dates, all data were standardized for time of initial entrance into torpor and recorded as the number of days postonset of hibernation and the percentage of the hibernation period. For example, $\dot{\mathrm{V}}_{2}$ of the group that entered torpor on December 1 was measured in late December; the midpoint of the bout occurred $23 \mathrm{~d}$ after onset of hibernation, which was at $13.4 \%$ of the hibernation period. The midpoint of the bout was used for plotting $\dot{\mathrm{V}}_{2}$ against time in the hibernation period (Fig. 3).

During arousal, marmots collected paper towels and added them to their nests. There was no instance of arousal as indicated by $T_{\mathrm{B}}$ that towels were not taken nor was there any time that towels were taken that $T_{\mathrm{B}}$ did not indicate arousal. Thus, these animals are active during arousal. The number of torpor bouts per animal averaged 19.2 \pm 1.7. Average bout length was longer for single young $(11.7 \pm 0.6 \mathrm{~d})$ than for young in a group $(9.9 \pm 0.7 \mathrm{~d}, P=0.062)$. The hibernation period was divided into segments of $30 \mathrm{~d}$ each. Mean bout length per $30 \mathrm{~d}$ for six animals with transmitters varied from 6.8 to $14.3 \mathrm{~d}$. Mean bout length increased through the first 150 $\mathrm{d}$ and then decreased until termination (Fig. 2). However, the number of days in torpor for each 30 -d period varied little after the first $30 \mathrm{~d}$ until the 210 -d period when the time torpid decreased as the time of termination approached (Fig. 2). Through the first $180 \mathrm{~d}$ of hibernation, the number of days of torpidity averaged $162.2 \pm 2.6$ (90.1\% of the time) for young hibernating singly and $147 \pm 7.1$ (81.7\% of the time) for groups of three. Both differences among months $(P=0.012)$ and between single and group hibernators $(P=0.036)$ were significant.

\section{Body Mass}

Body mass at onset of hibernation averaged $1,827 \pm 711.9 \mathrm{~g}$ and at termination averaged 1,304 $\pm 511.1 \mathrm{~g}$. Mass loss from onset to termination averaged $523 \pm 258.9 \mathrm{~g}$. The average loss represented $28.4 \% \pm 6.8 \%$ of onset mass. Daily mass loss (DML; $\mathrm{g} \mathrm{d}^{-1}$ ) averaged $2.51 \pm 1.08 \mathrm{~g}$. Both total mass loss $\left(r_{\mathrm{s}}=0.90\right)$ and daily mass loss $\left(r_{\mathrm{s}}=0.96\right)$ were directly related to onset mass $(P<0.01)$. Larger individuals lost more mass. Because it could be argued that the marmots in groups were 
not independent statistically, we compared group means $(N=2)$ with singles $(N=4)$. DML ( $\mathrm{mg} \mathrm{d}^{-1} \mathrm{~g}^{-1}$ onset mass) of $1.33 \pm 0.24$ for single marmots did not differ significantly (Mann-Whitney, $P=0.323$ ) from the $1.46 \pm 0.09$ of grouped marmots. DML, which is a measure of the rate of mass loss, was not significantly related to onset mass $\left(r_{\mathrm{s}}=-0.285, P>\right.$ 0.05).

\section{Bout Metabolism: Bout Characteristics}

Bout length in the metabolism chamber averaged $258.3 \pm$ $83.8 \mathrm{~h}(10.8 \pm 3.5 \mathrm{~d})$. The mean bout length is almost identical to the mean bout length measured in the hibernation rooms. For the three phases of the bout, the least time was spent in arousal (mean hours $=6.1 \pm 2.3$; mean percentage of time $=2.5 \pm 0.97$ ), more time was spent euthermic (mean hours $=33.0 \pm 11.1$; mean percentage of time $=13.7 \pm 6.3$ ), and most of the time was spent torpid (mean hours = $219.2 \pm 82.8$; mean percentage of time $=83.9 \pm 6.7$ ). Young in groups on average spent more time euthermic $(46.9 \mathrm{~h}$ per bout, $19.7 \%$ of bout time vs. $32.2 \mathrm{~h}, 13.8 \%$ ) and took longer to reach deep torpor ( $32.4 \mathrm{~h}$ per bout, $12.4 \%$ of bout time vs. $22.2 \mathrm{~h}, 9.5 \%$ ) than did single young. The mean percent time torpid is nearly the same as the mean of $82.7 \%$ for all animals in the hibernation rooms.

Bout length was significantly related to the time spent in torpor $\left(r_{\mathrm{s}}=0.98, P<0.01\right)$ and was unrelated to the time spent euthermic ( $r_{\mathrm{s}}=0.15, P \gg 0.05$ ). The period of torpor has two components, deep torpor and entrance, which is the time from the onset of torpor $\left(T_{\mathrm{B}}<30^{\circ} \mathrm{C}\right)$ to the onset of deep torpor (low, stable $\dot{\mathrm{V}}_{2}$ ). Entrance required a minor part of torpor (mean hours $=26.0 \pm 9.7$; mean percent time $=12.9 \pm 6.1$ ) and was unrelated to bout length $\left(r_{\mathrm{s}}=0.1, P \gg 0.05\right)$, length of torpor $\left(r_{\mathrm{s}}=0.14, P \gg 0.05\right)$, or body mass $\left(r_{\mathrm{s}}=0.31, P>\right.$ 0.05). Most of the time torpid was spent in deep torpor (mean hours $=193.3 \pm 81.8$; mean percent time $=87.1 \pm 6.9$ ); time in deep torpor was significantly correlated with time torpid $\left(r_{\mathrm{s}}=0.96, P<0.01\right)$ and with bout length $\left(r_{\mathrm{s}}=0.93, P<0.01\right)$. Thus, as torpor bouts became longer, disproportionally more time was spent at the low energy state of torpor, especially deep torpor.

Mean $T_{\mathrm{B}}$ of individuals during deep torpor at $6^{\circ} \mathrm{C}$ varied from $8.15^{\circ}$ to $9.76^{\circ} \mathrm{C}$. The mean $T_{\mathrm{B}}$ among individuals was $8.94^{\circ} \mathrm{C}$ and was inversely related to bout length $\left(r_{\mathrm{s}}=-0.72\right.$, $P \simeq 0.01)$ and time torpid $\left(r_{\mathrm{s}}=-0.77, P<0.01\right)$; the longer the bout, the lower was the mean $T_{B}$. $T_{B}$ decreased slowly over time during deep torpor (Fig. 1), and $\dot{\mathrm{V}}_{2}$ remained stable and did not increase to prevent the decline in $T_{\mathrm{B}}$. Thus, the lower $T_{\mathrm{B}}$ is probably a consequence of passive heat loss over a longer time period spent in deep torpor before arousal increases $\dot{\mathrm{V}}_{2}$ and $T_{\mathrm{B}}$ (Heldmaier et al. 1993; Ortmann and Heldmaier 2000).

\section{Bout Metabolism: Oxygen Consumption}

During the total bout, $\dot{\mathrm{V}}_{2}$ at $6^{\circ} \mathrm{C}$ varied from 28.1 to 213.6 $\mathrm{mL} \mathrm{h}^{-1}$ and was directly related to body mass $\left(r_{\mathrm{s}}=0.77, P<\right.$ $0.01)$ and mean $T_{\mathrm{B}}$ during deep torpor $\left(r_{\mathrm{s}}=0.67, P<0.05\right)$ and negatively related to bout length $\left(r_{\mathrm{s}}=-0.69, P<0.05\right)$. Massspecific bout $\dot{\mathrm{V}}_{2}$ varied from 0.017 to $0.048 \mathrm{~mL} \mathrm{~g}^{-1} \mathrm{~h}^{-1}$ and was also related positively to mean $T_{\mathrm{B}}$ during deep torpor $\left(r_{\mathrm{s}}=0.94, P<0.01\right)$ and negatively to bout length $\left(r_{\mathrm{s}}=\right.$ $-0.69, P<0.05)$. Both $\dot{\mathrm{V}}_{2}\left(r_{\mathrm{s}}=-0.77, P<0.01\right)$ and massspecific $\dot{\mathrm{Vo}}_{2}\left(r_{\mathrm{s}}=-0.76, P<0.01\right)$ were negatively related to time spent in deep torpor. The more time spent in deep torpor, the lower is bout $\dot{\mathrm{V}}_{2}$.

Bout $\dot{\mathrm{V}}_{2}$ decreases with increasing time in deep torpor because mass-specific $\dot{\mathrm{V}}_{2}$ during deep torpor varied from 0.0049 to $0.0102 \mathrm{~mL} \mathrm{~g}^{-1} \mathrm{~h}^{-1}$, whereas $\dot{\mathrm{Vo}}_{2}$ during euthermy varied from 0.122 to $0.2005 \mathrm{~mL} \mathrm{~g}^{-1} \mathrm{~h}^{-1}$. Thus, more time spent at the low-energy state of deep torpor and less time at the highenergy state of euthermy reduces mean hourly metabolic rate and total energetic costs of a torpor bout.

Variation of $\dot{\mathrm{V}}_{2}$ among torpor bouts was best explained by plotting bout $\dot{\mathrm{V}}_{2}$ as a function of when in the hibernation period $\dot{\mathrm{VO}}_{2}$ was measured. $\dot{\mathrm{V}}_{2}$ was plotted as a function of the number of days past the day of immergence and as the percentage of the hibernation period when $\dot{\mathrm{V}}_{2}$ was measured. The percentage of the hibernation period provided higher $R^{2}$ values than days past immergence and is presented here. The relationship was curvilinear (Fig. 3) and was similar in shape to the circannual rhythm of $\dot{\mathrm{V}}_{2}$ of euthermic adult yellow-bellied marmots (Ward and Armitage 1981).

Because mass-specific bout $\dot{V}_{\mathrm{O}_{2}}$ was positively correlated with mean $T_{\mathrm{B}}$ and negatively correlated with time spent in deep torpor, mean $T_{\mathrm{B}}$ and percent time in deep torpor were plotted as a function of the percentage of the hibernation period. The

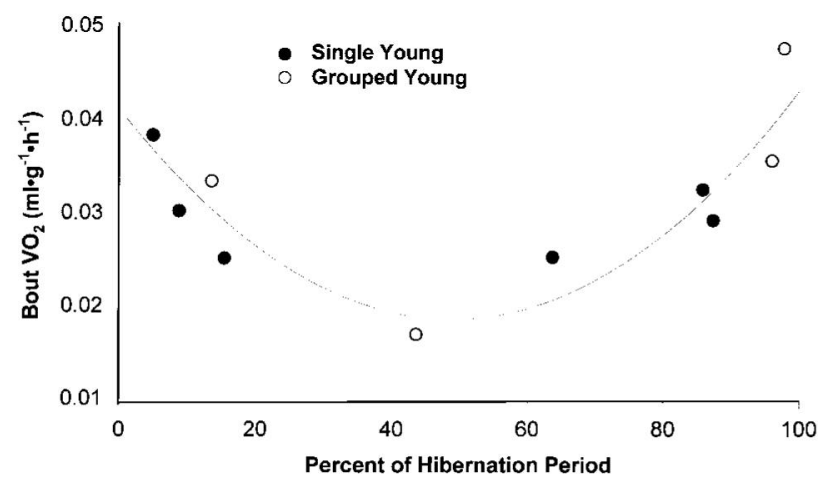

Figure 3. Bout $\dot{\mathrm{V}}_{2}$ as a function of the time in the hibernation period. $\dot{\mathrm{V}}_{2}=0.045-0.000901 X+0.0000094 X^{2}, R^{2}=0.79 . X=$ percentage of the hibernation period. Bout measures oxygen consumption through one complete torpor bout, which includes arousal, euthermy, and torpor (Fig. 1) and is the hourly mean averaged over the entire bout. 
relationships were curvilinear (Fig. 4) and significant (percent time in deep torpor, $P=0.06, R^{2}=0.55 ; T_{\mathrm{B}}, P=0.003$, $R^{2}=0.81$.

\section{Temperature Effects}

$\dot{\mathrm{V}}_{2}$ for the five measurements during deep torpor averaged $0.0068 \pm 0.0018 \mathrm{~mL} \mathrm{O}_{2} \mathrm{~g}^{-1} \mathrm{~h}^{-1}$ at $6^{\circ} \mathrm{C}, 0.0073 \pm 0.0015 \mathrm{~mL} \mathrm{O}_{2}$ $\mathrm{g}^{-1} \mathrm{~h}^{-1}$ at $4^{\circ} \mathrm{C}$, and $0.0121 \pm 0.0017 \mathrm{~mL} \mathrm{O}_{2} \mathrm{~g}^{-1} \mathrm{~h}^{-1}$ at $2^{\circ} \mathrm{C}$. $\dot{\mathrm{V}}_{2}$ at $2^{\circ} \mathrm{C}$ was significantly greater than that at $4^{\circ} \mathrm{C}$ and $6^{\circ} \mathrm{C}$ $(P=0.001)$. The values for the two groups of young fell within the range of values for the three singles.

Complete bouts at $2^{\circ} \mathrm{C}$ were measured for one group and one single male young. There was minimal difference in bout $\dot{\mathrm{V}}_{2}$ at $6^{\circ} \mathrm{C}\left(0.0338\right.$ vs. $\left.0.0329 \mathrm{~mL} \mathrm{O}_{2} \mathrm{~g}^{-1} \mathrm{~h}^{-1}\right)$. At $2^{\circ} \mathrm{C}$, bout $\dot{\mathrm{V}}_{2}$ increased to $0.0426 \mathrm{~mL} \mathrm{O}_{2} \mathrm{~g}^{-1} \mathrm{~h}^{-1}$ for the group and to $0.0513 \mathrm{~mL} \mathrm{O}_{2} \mathrm{~g}^{-1} \mathrm{~h}^{-1}$ for the single young. $\dot{\mathrm{V}}_{2}$ of the single male was lower than that of the group during euthermy and torpor and much higher during the brief arousal. However, the single male spent $21 \%$ of the bout time in euthermy compared with $10 \%$ by the group. The greater proportion of time at the more expensive euthermic state resulted in the higher bout $\dot{\mathrm{V}}_{2}$. The less time spent euthermic and the lower costs of arousal by the group (51\% of the cost of the single male) suggest that group hibernation may be a benefit only at low $T_{\mathrm{E}}$. However, our sample size of two precluded statistical analysis and a much larger sample size is required to determine whether these results reflect individual variation or represent a group benefit at low $T_{\mathrm{E}}$.

Body temperature during deep torpor averaged $8.74^{\circ} \pm$ $0.49^{\circ} \mathrm{C}$ at $T_{\mathrm{E}}=6^{\circ} \mathrm{C}, 6.99^{\circ} \pm 0.53^{\circ} \mathrm{C}$ at $T_{\mathrm{E}}=4^{\circ} \mathrm{C}$, and $5.93^{\circ} \pm 0.61^{\circ} \mathrm{C}$ at $T_{\mathrm{E}}=2^{\circ} \mathrm{C}$. Thus, mean $T_{\mathrm{B}}$ decreased as $T_{\mathrm{E}}$ decreased, and $T_{\mathrm{B}}-T_{\mathrm{E}}$ increased from $2.74^{\circ} \mathrm{C}$ at $T_{\mathrm{E}}=6^{\circ} \mathrm{C}$ to $3.93^{\circ} \mathrm{C}$ at $T_{\mathrm{E}}=2^{\circ} \mathrm{C}$. The effect of $T_{\mathrm{E}}$ on $T_{\mathrm{B}}$ was highly significant $(P<0.001)$; the $T_{\mathrm{B}}$ values at $6^{\circ} \mathrm{C}, 4^{\circ} \mathrm{C}$, and $2^{\circ} \mathrm{C}$ significantly differed from each other. Although the $T_{\mathrm{B}}-T_{\mathrm{E}}$ gradient increased as $T_{\mathrm{E}}$ decreased, resulting in higher $\dot{\mathrm{V}}_{\mathrm{O}_{2}}$, the increase in $\dot{\mathrm{V}}_{\mathrm{O}_{2}}$ would have been much greater if $T_{\mathrm{B}}$ had been maintained at the value at $T_{\mathrm{E}}=6^{\circ} \mathrm{C}$. Thus, by allowing the $T_{\mathrm{B}}$ to decrease at lower $T_{\mathrm{E}}$, energy costs were reduced. We calculated conductance (C) from the following formula: $C=\mathrm{MR} / T_{\mathrm{B}}-T_{\mathrm{E}}$, where $\mathrm{MR}=$ metabolic rate and $C=\mathrm{mL} \mathrm{O}_{2} \mathrm{~g}^{-1} \mathrm{~h}^{-1}{ }^{\circ} \mathrm{C}$. $C$ was $0.00249 \pm 0.0003$ at $6^{\circ} \mathrm{C}, 0.00254 \pm 0.0005$ at $4^{\circ} \mathrm{C}$, and increased significantly $(P=0.057)$ to $0.0031 \pm 0.0003$ at $2^{\circ} \mathrm{C}$. We used the equation $\mathrm{MR}=C\left(T_{\mathrm{B}}-T_{\mathrm{E}}\right)$ to calculate theoretical $\dot{\mathrm{V}}_{2}$ values at $4^{\circ} \mathrm{C}$ and $2^{\circ} \mathrm{C}$. We assumed that the animals maintained the same $T_{\mathrm{B}}$ at $4^{\circ} \mathrm{C}$ and $2^{\circ} \mathrm{C}$ that they maintained at $6^{\circ} \mathrm{C}$. Therefore, theoretical $T_{\mathrm{B}}-T_{\mathrm{E}}$ increased to $4.74^{\circ} \mathrm{C}$ at $4^{\circ} \mathrm{C}$ and $6.74^{\circ} \mathrm{C}$ at $2^{\circ} \mathrm{C}$. The theoretical $\dot{V O}_{2}\left(\mathrm{~mL} \mathrm{O}_{2} \mathrm{~g}^{-1} \mathrm{~h}^{-1}\right)$ was 0.0119 at $4^{\circ} \mathrm{C}$ and 0.0207 at $2^{\circ} \mathrm{C}$. Thus, by allowing $T_{\mathrm{B}}$ to decrease and thus reducing the $T_{\mathrm{E}}-T_{\mathrm{B}}$ gradient and rate of heat loss, the marmots avoided an additional $63 \%$ increase in $\dot{\mathrm{V}}_{2}$ at $4{ }^{\circ} \mathrm{C}$ and a $71 \%$ increase at $2^{\circ} \mathrm{C}$.

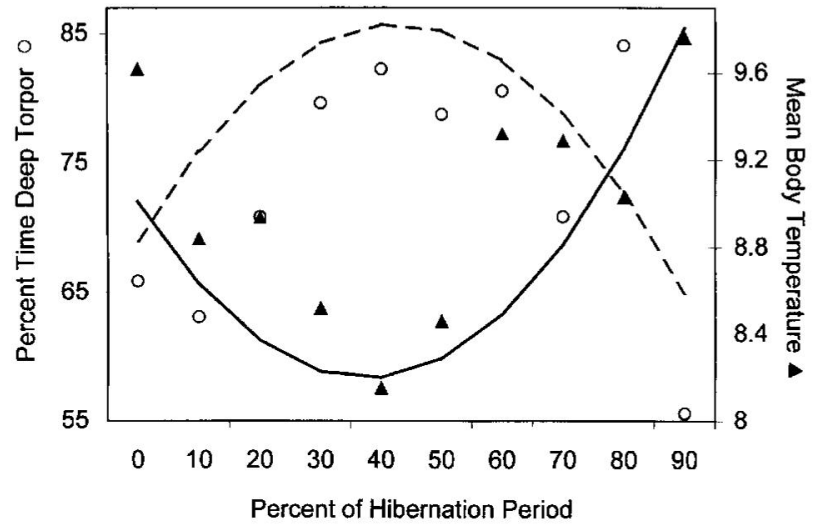

Figure 4. Percent time in deep torpor and mean body temperature $\left(T_{\mathrm{B}}\right)$ as a function of time in the hibernation period. Percent time in deep torpor $=60.19+0.973 X-0.0093 X^{2} . \quad T_{\mathrm{B}}=9.51-0.055 X+$ $0.00058 X^{2}$. Solid line represents $T_{\mathrm{B}}$; dashed line represents time in deep torpor.

\section{Energy Budget}

The energy budget varied among the 30 - $\mathrm{d}$ periods (Table 1 ). Because the animals were standardized to the first day of torpor rather than to calendar month, the energy budget is essentially the same as the cost of hibernation (French 1992). For the hibernation period, marmots were torpid $82.7 \%$ of the time, but this required only $17.6 \%$ of the energy expenditure; thus, activity used $82.4 \%$ of the energy in $17.3 \%$ of the time. The relatively high active AMMR in the first $30 \mathrm{~d}$ occurred because marmots were arousing frequently; that is, bout lengths were short and animals were torpid $77 \%$ of the time (Fig. 2; Table 1). In the subsequent four time periods, active AMMR was relatively low because marmots were torpid more than $88 \%$ of the time. Although marmots maintained a high level of torpidity in the 180-d time period, active and torpid AMMR increased because of the upturn in the seasonal curve (Fig. 3; Table 1). Three animals terminated hibernation at $175 \mathrm{~d}$; these $5 \mathrm{~d}$ of euthermy for three animals during the 180-d time period little affected the energy budget. In the 210-d time period, energy costs increased in large part because the time spent euthermic increased before termination in the three marmots that terminated hibernation during this period. One of these young was euthermic for $19 \mathrm{~d}$ before reentering hibernation for two short bouts and then remained euthermic. Reimmergence commonly occurs in juvenile yellow-bellied marmots unless they are fed (French 1988, 1990). Four animals hibernated for an average of $15 \mathrm{~d}$ in the final time period, and the energy budget is calculated for those $15 \mathrm{~d}$ but extrapolated to $30 \mathrm{~d}$ so that the time periods are comparable. Energy costs were highest in the final time period because the percent time torpid decreased and the upturn of the seasonal cycle further increased $\dot{\mathrm{V}}_{2}$. 
Table 1: Energy budgets for young yellow-bellied marmots hibernating at $6^{\circ} \mathrm{C}$

\begin{tabular}{|c|c|c|c|c|c|}
\hline \multirow{2}{*}{$\begin{array}{l}\text { Time Period } \\
\text { (d) }(N)\end{array}$} & \multirow{2}{*}{$\begin{array}{l}\text { Time Spent } \\
\text { Torpid (\%) }\end{array}$} & \multicolumn{2}{|c|}{$\operatorname{AMMR}\left(\mathrm{LO}_{2}\right)$} & \multicolumn{2}{|c|}{ Energy Saved (\%) } \\
\hline & & Active & Torpid & Winter & Summer \\
\hline $30(10)$ & 77.6 & 44.9 & 10.2 & 68.2 & 86.9 \\
\hline $60(10)$ & 88.3 & 19.0 & 8.9 & 81.0 & 93.1 \\
\hline $90(10)$ & 90.0 & 14.3 & 7.3 & 84.1 & 94.5 \\
\hline $120(10)$ & 89.3 & 15.2 & 6.4 & 84.3 & 94.2 \\
\hline $150(10)$ & 91.0 & 14.1 & 6.6 & 86.4 & 94.2 \\
\hline $180(10)$ & 87.3 & 23.4 & 7.0 & 82.7 & 91.2 \\
\hline $210(7)$ & 71.7 & 63.6 & 6.9 & 66.1 & 78.5 \\
\hline Final (4) & 66.6 & 85.6 & 7.0 & 63.9 & 71.4 \\
\hline Mean & 82.7 & 35.0 & 7.5 & 77.1 & 88.0 \\
\hline
\end{tabular}

Note. Summer euthermic $\dot{\mathrm{V}}_{\mathrm{O}_{2}}$ ranged from 324.2 to $423.7 \mathrm{~L}$, and winter euthermic $\dot{\mathrm{V}}_{\mathrm{O}_{2}}$ varied from 135.8 to $256.7 \mathrm{~L}$ per time period. $N=$ number of young hibernating. Average monthly metabolic rate (AMMR) is expressed in liters of oxygen $\left(\mathrm{LO}_{2}\right)$. Total AMMR $=$ active + torpid. Active AMMR is the sum of euthermy + arousal.

We calculated energy savings as a means of quantifying the energetic benefits of hibernation and as a means for comparing the energetics of hibernation among species of marmots. The energy savings by hibernation can be estimated by comparing energy expenditures during hibernation with those of euthermic marmots (Heldmaier et al. 1993). Energy saved (ES) was calculated for both summer and winter euthermy to determine whether the decrease in euthermic metabolism from summer to winter made an important contribution to ES. ES was calculated from the following equation: ES $(\%)=1-$ (total AMMR/euthermic AMMR) $\times 100$. For winter ES, we used values calculated from the following equation: Euthermic $\dot{\mathrm{V}}_{2}(\mathrm{~mL}$ $\left.\mathrm{h}^{-1}\right)=0.167336-0.00113 X+0.00000647 X^{2}, P=0.01, R^{2}=$ 0.89 . For summer ES, we used postmolt $\dot{\mathrm{V}}_{2}$ for summer active young (Armitage and Salsbury 1992) and adjusted the values for mass loss during the hibernation period.

Winter ES varied from $63.9 \%$ to $86.4 \%$ and averaged $77.1 \%$. Summer ES varied from $71.4 \%$ to $94.5 \%$ and averaged $88.0 \%$ (Table 1). The difference in ES between summer and winter can be attributed to the seasonal decline in $\dot{\mathrm{V}}_{2}$ during the hibernation season, which reduces winter euthermy and thus decreases the amount of energy saved compared with summer ES, when euthermic $\dot{\mathrm{V}}_{2}$ is higher. Thus, the seasonal decline in metabolism contributes significantly to the reduced energy expenditures during the hibernation season as $\dot{\mathrm{V}}_{2}$ is decreased even when the marmots are euthermic.

\section{Discussion}

\section{Group versus Single Hibernation}

Several lines of evidence indicate that young yellow-bellied marmots did not benefit from group hibernation: DML was higher in grouped than in single young, groups spent fewer days in torpidity, groups spent more time euthermic and took more time to reach deep torpor during $\dot{\mathrm{V}}_{2}$ measurements, and $\dot{\mathrm{V}}_{2}$ did not differ between grouped and single young during deep torpor at $2^{\circ} \mathrm{C}$. Thus, the young in groups spent more time at energetically costly phases of the torpor bout than single young, and this cost was not compensated by a lower $\dot{\mathrm{V}}_{2}$. The reason for the longer time at the energetically costly phases apparently was a lack of synchrony among the members of the group. Members within each group increased $\dot{\mathrm{V}}_{2}$ at different times during euthermy and descent into torpor, possibly caused by disturbance by other group members, which delayed reaching deep torpor (Fig. 5). For example, groups 16 and 37 required $84 \mathrm{~h}$ and $96 \mathrm{~h}$, respectively, whereas male 23 needed only $45 \mathrm{~h}$ to reach deep torpor. Thus, asynchrony among the young increased energy expenditure, and group hibernation may be costly rather than beneficial for yellow-bellied marmots. By contrast, the time course of changes between torpor and periodic arousals was generally well synchronized among alpine marmots (Marmota marmota) hibernating in groups (Ruf and Arnold 2000). Interestingly, group synchrony in alpine marmots was impaired by the presence of juveniles. Reduced group synchrony was disadvantageous for adults but advantageous for juveniles; heat loss of juveniles was greatly reduced because of heat provided by the adults. Juveniles also reduce heat loss, but to a much lower degree, when huddling in the absence of parents or full sibs (Ruf and Arnold 2000). When heat loss is reduced, less energy is required to maintain $T_{\mathrm{B}}$.

Juvenile yellow-bellied marmot littermates hibernate in the same hibernaculum and immerge within a 1-d to 2-d period (Lenihan and Van Vuren 1996). Littermates emerged as yearlings within a few days of each other the following spring. Nonreproductive females and the adult male hibernate a week or more before the reproductive female hibernates, and young may remain active for an additional $2 \mathrm{wk}$ (Kilgore and Armitage 1978). Yellow-bellied marmots typically hibernate singly except 


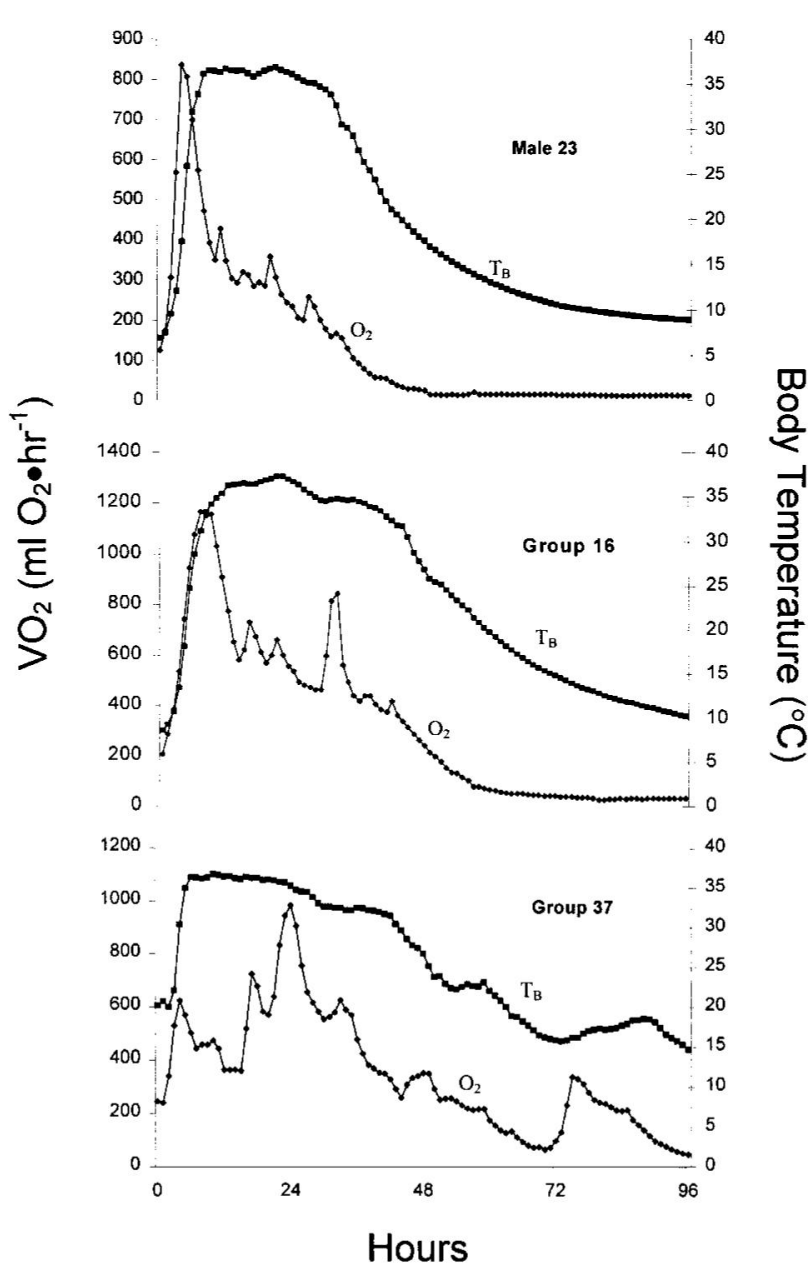

Figure 5. $\dot{\mathrm{V}}_{\mathrm{O}_{2}}\left(\mathrm{~mL} \mathrm{~h}^{-1}\right)$ and body temperature $\left(T_{\mathrm{B}}\right)$ during arousal and descent into deep torpor. Male 23 typifies a young marmot hibernating alone; groups 16 and 37 exemplify asynchrony in the groups of three young during the torpor cycle.

for littermate young. By contrast, alpine marmot families, which typically consist of the territorial pair, a variable number of nonreproductive adults, and juveniles (Mann et al. 1993), immerge as a group. Group hibernation makes possible social thermoregulation and hibernation in large groups reduces winter mortality (Ruf and Arnold 2000).

In yellow-bellied marmots, in which females may form social groups of two to five adults, the most common group size is one, and mean size is 1.38 females (Armitage and Schwartz 2000). Therefore, there is little opportunity for group hibernation, except for littermate juveniles. Because DML in one group of young (mean $=1.39$ ) was similar to that of the singles $($ mean $=1.33)$, it seemed that over a long period and with a much larger sample size, there could be an advantage to group hibernation. Therefore, we tested whether there were any sig- nificant differences in survivorship of young yellow-bellied marmots hibernating in groups of different sizes. We extracted litter sizes from the demographic data set collected from 1962 through 2000 and subtracted all known cases of summer mortality to produce hibernating litter sizes that ranged from one to eight. Mean percent survival varied from $34.3 \%$ for litters of eight to $58.8 \%$ for litters of three. There was no significant effect of litter size on percent survival (ArcSine transformed data, $N=256, F=0.96, P=0.46)$. This result indicates that there is no advantage to possible social thermoregulation or that other causes of mortality negate any social thermoregulation advantage. The field data support our laboratory results that demonstrate no advantages to group hibernation.

\section{Seasonal Changes}

The pattern of seasonal changes in bout length, the length of torpor, $T_{\mathrm{B}}$, and bout $\dot{\mathrm{V}}_{2}$ (Figs. 2-4; see also Ward and Armitage 1981; Heldmaier et al. 1993) appears to be driven by an endogenous circannual rhythm. This rhythm is persistent and independent of the constant darkness of hibernation (Concannon et al. 1997) and requires only natural photoperiod to entrain the endogenous circannual cycle (Concannon et al. 1993). Seasonal variation in $T_{\mathrm{B}}$ is not necessary for circannual changes in circadian organization of ground squirrels (Freeman and Zucker 2000). Photoperiodic entrainment occurs under controlled temperatures in laboratory marmots (Concannon et al. 1997) and apparently under fluctuating temperatures in the natural environment because translocated marmots maintained in outdoor enclosures shift their annual cycle to conform to the local conditions (Thompson 1979). Both field and laboratory marmots may require up to $3 \mathrm{yr}$ to shift the phase of the rhythm by 2-6 mo (Davis and Finnie 1975; Thompson 1979; Concannon et al. 1997). Presumably, young marmots in their first year of life are entrained by photoperiod. Because our young were exposed to $8 \mathrm{wk}$ of natural photoperiod and because circannual rhythms persist intact in a $12 \mathrm{~L}: 12 \mathrm{D}$ photoperiod (Concannon et al. 1997), we conclude that our animals were entrained to the circannual rhythm.

The circannual rhythm reduction in bout $\dot{\mathrm{V}}_{2}$ through the first half of the hibernation season and the continued low $\dot{\mathrm{V}}_{2}$ through about $90 \%$ of the hibernation season greatly reduces the costs of hibernation (Fig. 3; Table 1). Only as the time of emergence nears does $\dot{\mathrm{V}}_{2}$ markedly increase; this increase likely prepares the marmots for posthibernation activity. For example, spermatogenic activity is greatest at emergence (Christian et al. 1972) and is initiated when animals are euthermic; however, less time spent torpid decreases the time needed for spermatogenesis (Barnes et al. 1987). In addition, the digestive tract, which undergoes constriction (Rausch and Rausch 1971; Bassano et al. 1992), must be upregulated at emergence (Hume et al. 2002), and the synthesis of new epithelial cells occurs during euthermy (Carey 1993). Marmots 
need to initiate these activities as early as possible to have time to accomplish them in the short active season (Armitage 1981, 1998; French 1988) and prepare for the subsequent hibernation. Thus, there seems to be a trade-off between the requirements of conserving energy and initiating posthibernation activity. The restoration of normothermic metabolism before emergence permits marmots to respond to the variation in the timing of the spring season and initiate aboveground activity early when conditions permit. However, marmots cannot delay reproduction too late in the spring because time becomes insufficient for reproductive females and young to prepare for hibernation and winter mortality increases (Armitage et al. 1976; Armitage 1994). Thus, the circannual cycle induces spontaneous emergence in adults, but young may delay emergence until food is available (French 1988, 1990).

The pattern of circannual changes in $\dot{\mathrm{V}}_{2}$ presents two problems. First, the functional significance of the increase in $\dot{\mathrm{V}}_{2}$ in late hibernation requires investigation. Second, the comparison of $\dot{\mathrm{V}}_{2}$ values from different studies is problematic because it is highly unlikely that measurements were made at the same phase of the circannual cycle.

\section{Hibernation Energetics}

In general, yellow-bellied marmots are energy conservers (Armitage 1998) and are more efficient than other species of marmots. For example, the mean winter ES of $77.1 \%$ for young Marmota flaviventris was much higher than the $43.2 \%$ for Marmota monax (Armitage et al. 2000) and the $43.8 \%$ for M. marmota (Heldmaier et al. 1993). Several energy-conserving mechanisms function during hibernation. First, the seasonal increase in bout and torpor length and decrease in bout $\dot{\mathrm{V}}_{2}$ reduced energetic costs.

Second, throughout most of the hibernation period (days 60 to 180 ), the percent time torpid averages $89.2 \%$, regardless of bout length (Fig. 2; Table 1). Spending most of their bouts in torpor further reduces energy costs.

Third, following a periodic arousal, descent into torpor is characterized by the decline in $\dot{\mathrm{V}}_{2}$ before the decline in $T_{\mathrm{B}}$ (Fig. 1). The decline occurs much more rapidly than it would if decline in $\dot{\mathrm{V}}_{2}$ followed the decline in $T_{\mathrm{B}}$ and thus saves considerable energy (Woods et al. 2002). This pattern was also reported for M. monax (Lyman 1958; Armitage et al. 2000) and M. marmota (Ortmann and Heldmaier 2000). The lack of a relationship between decline ( = entrance into torpor) and body mass or bout length indicates that this mechanism is of critical importance for conserving energy and is decoupled from some of the other factors that affect $\dot{\mathrm{V}}_{2}$.

Fourth, by allowing $T_{\mathrm{B}}$ to decline at lower $T_{\mathrm{E}}$, energy is saved over that which would be required to maintain $T_{\mathrm{B}}$ at a higher level. It appears that yellow-bellied marmots are minimizing energy expenditures and regulating $T_{\mathrm{B}}$ accordingly. However, there may be a $T_{\mathrm{B}}$ of about $5.5^{\circ} \mathrm{C}$ that is the minimal $T_{\mathrm{B}}$ that is tolerated (Armitage et al. 2003), but the minimal $T_{\mathrm{B}}$ has not been clearly determined.

\section{Hibernation Strategy}

This study supports earlier reports that yellow-bellied marmots primarily use energetic efficiency as their major hibernation strategy (Armitage et al. 2000, 2003). Hibernation in groups did not benefit young $M$. flaviventris as evidenced by the similarity in DML in single and group hibernators. Marmota marmota measured singly have higher DML than M. flaviventris (Armitage et al. 2000) and have evolved social thermoregulation as a major hibernation strategy (Arnold 1993). Social thermoregulation primarily benefits young, but data on the metabolism of young $M$. marmota hibernating singly or in groups are not available; thus, it is not possible to directly compare the energy budgets of young of these two species. If the energy budget of young $M$. marmota follows a pattern similar to that of adult $M$. marmota, then we predict that individual young M. marmota will have higher $\dot{\mathrm{V}}_{2}$ and DML than young $M$. flaviventris.

Marmota marmota and M. flaviventris occur in different subgenera in the monophyletic Marmota (Kruckenhauser et al. 1998; Steppan et al. 1999). Except for M. monax, which does not live in social groups, the remaining species in the subgenus Marmota live in extended family groups similar to that of $M$. marmota (Armitage 2000). By living in extended family groups, the opportunity for social thermoregulation was present and became a major hibernation strategy. By contrast, the less social M. flaviventris, which lives in female kin groups (Armitage 2000), evolved energetic efficiency as a major strategy. The asocial $M$. monax relies primarily on a combination of large size and a short hibernation season (Armitage et al. 2000). The other members of the subgenus Petromarmota live in restricted family groups in which the opportunity for social thermoregulation is limited. The age groups that provide the social thermoregulation in M. marmota are not present in the social groups in the species in this subgenus (Armitage 2000). It would be of considerable interest to determine the hibernation energetics of these species (Marmota olympus, Marmota caligata, Marmota vancouverensis) and of additional species in the subgenus Marmota to determine the relative importance of the three major hibernation strategies.

\section{Acknowledgments}

Maintenance of animals followed animal care guidelines. We thank Dr. James F. Bresnahan for performing the surgeries and Sharon Lee Green for typing the manuscript. 


\section{Literature Cited}

Armitage K.B. 1981. Sociality as a life history tactic of ground squirrels. Oecologia 48:36-49.

- 1994. Unusual mortality in a yellow-bellied marmot population. Pp. 5-13 in V. Rumiantsev, ed. Actual Problems of Marmots Investigation. ABF PH, Moscow.

$\rightarrow$. 1998. Reproductive strategies of yellow-bellied marmots: energy conservation and differences between the sexes. J Mammal 79:385-393.

$\rightarrow$. 1999. Evolution of sociality in marmots. J Mammal 80:1-10.

. 2000. The evolution, ecology, and systematics of marmots. Oecol Mont 9:1-18.

- 2002. Social dynamics of yellow-bellied marmots: strategies for evolutionary success. Pp. 9-16 in K.B. Armitage and V.Y. Rumiantsev, eds. Holarctic Marmots as a Factor of Biodiversity. ABF PH, Moscow.

Armitage K.B., D.T. Blumstein, and B.C. Woods. 2003. Energetics of hibernating yellow-bellied marmots (Marmota flaviventris). Comp Biochem Physiol 134A:101-114.

$\rightarrow$ Armitage K.B. and J.F. Downhower. 1974. Demography of yellow-bellied marmot populations. Ecology 55:1233-1245.

$\rightarrow$ Armitage K.B., J.F. Downhower, and G.E. Svendsen. 1976. Seasonal changes in the weights of marmots. Am Midl Nat 96: $36-51$.

$\rightarrow$ Armitage K.B. and C.M. Salsbury. 1992. Factors affecting oxygen consumption in wild-caught yellow-bellied marmots (Marmota flaviventris). Comp Biochem Physiol 103A:729737.

$\rightarrow$. 1993. The effect of molt on oxygen consumption of yellow-bellied marmots (Marmota flaviventris). Comp Biochem Physiol 106A:667-670.

$\rightarrow$ Armitage K.B. and O.A. Schwartz. 2000. Social enhancement of fitness in yellow-bellied marmots. Proc Natl Acad Sci USA 97:12149-12152.

Armitage K.B., B.C. Woods, and C.M. Salsbury. 2000. Energetics of hibernation in woodchucks (Marmota monax). Pp. 7380 in G. Heldmaier and M. Klingenspor, eds. Life in the Cold. Springer, Berlin.

$\rightarrow$ Arnold W. 1990. The evolution of marmot sociality. II. Costs and benefits of joint hibernation. Behav Ecol Sociobiol 27: 239-246.

- 1993. Energetics of social hibernation. Pp. 65-80 in C. Carey, G.L. Florant, B.A. Wunder, and B. Horwitz, eds. Life in the Cold. Westview, Boulder, Colo.

$\rightarrow$ Arnold W., G. Heldmaier, S. Ortmann, H. Pohl, T. Ruf, and S $\rightarrow$ Steinlechner. 1991. Ambient temperatures in hibernacula and their energetic consequences for alpine marmots (Marmot $\rightarrow$ marmota). J Therm Biol 16:223-226.

$\rightarrow$ Barnes B.M., P. Licht, and I. Zucher. 1987. Temperature de-

pendence of in vitro androgen production in testes fron $\rightarrow$ Lenihan C. and D. Van Vuren. 1996. Growth and survival of hibernating ground squirrels, Spermophilus lateralis. Can J Zool 65:3020-3023.

Bassano B., B. Sabatier, L. Rossi, and E. Macchi. 1992. Parasitic fauna of the digestive tract of Marmota marmota in the western Alps. Pp. 13-24 in B. Bassano, P. Durio, U. Gallo Orsi, and E. Macchi, eds. First International Symposium on Alpine Marmot and on genus Marmota, St. Vincent, Italy, October. Carey H.V. 1993. Regulation of gut structure and function in hibernators. Pp. 155-165 in C. Carey, G.L. Florant, B.A. Wunder, and B. Horowitz, eds. Life in the Cold, Westview, Boulder, Colo.

$\rightarrow$ Christian J.J., E. Steinberger, and J.D. McKinney. 1972. Annual cycle of spermatogenesis and testis morphology in woodchucks. J Mammal 53:708-716.

$\rightarrow$ Concannon P., P. Roberts, B. Baldwin, H. Erb, and B. Tennant. 1993. Alteration of growth, advancement of puberty, and season-appropriate circannual breeding during 28 months of photoperiod reversal in woodchucks (Marmota monax). Biol Reprod 48:1057-1070.

Concannon P., P. Roberts, B. Baldwin, and B. Tennant. 1997. Long-term entrainment of circannual reproductive and metabolic cycles by northern and southern hemisphere photoperiods in woodchucks (Marmota monax). Biol Reprod 57: 1008-1015.

$\rightarrow$ Davis D.E. and E.P. Finnie. 1975. Entrainment of circannual rhythm in weight of woodchucks. J Mammal 56:199-203.

$\rightarrow$ Davis D.E. and J. Ludwig. 1981. Mechanism for decline in a woodchuck population. J Wildl Manag 45:658-668.

$\rightarrow$ Freeman D.A. and I. Zucker. 2000. Temperature independence of circannual variation in circadian rhythms of goldenmantled ground squirrels. J Biol Rhythms 15:336-343.

French A.R. 1988. The patterns of mammalian hibernation. Am Sci 76:569-575.

$\rightarrow-$. 1990. Age-class differences in the pattern of hibernation in yellow-bellied marmots, Marmota flaviventris. Oecologia 82:93-96.

- 1992. Mammalian dormancy. Pp. 105-121 in T.E. Tomasi and T.H. Horton, eds. Mammalian Energetics. Comstock, Ithaca, N.Y.

Heldmaier G., S. Ortmann, and G. Körtner. 1993. Energy requirements of hibernating alpine marmots. Pp. 175-183 in C. Carey, G.L. Florant, B.A. Wunder, and B. Horwitz, eds. Life in the Cold. Westview, Boulder, Colo.

$\rightarrow$ Hume I.D., C. Beiglböck, T. Ruf, F. Frey-Roos, U. Bruns, and W. Arnold. 2002. Seasonal changes in morphology and function of the gastrointestinal tract of free-living alpine marmots (Marmota marmota). J Comp Physiol B 172:197-207.

Kilgore D.L., Jr., and K.B. Armitage. 1978. Energetics of yellowbellied marmot populations. Ecology 59:78-88.

$\rightarrow$ Kruckenhauser L., W. Pinsker, E. Haring, and W. Arnold. 1998. Marmot phylogeny revisited: molecular evidence for a diphyletic origin of sociality. J Zool Syst Evol Res 37:49-56. 
juvenile yellow-bellied marmots (Marmota flaviventris). Can J Zool 74:297-302.

Lyman C.P. 1958. Oxygen consumption, body temperature and heart rate of woodchucks entering hibernation. Am J Physiol 194:83-91.

Lyman C.P., J.S. Willis, A. Malan, and L.C.H. Wang. 1982. Hibernation and Torpor in Mammals and Birds. Academic Press, New York.

Mann C.S., E. Macchi, and G. Janeau. 1993. Alpine marmot (Marmota marmota, L). IBEX J Mt Ecol 1:17-30.

Ortmann S. and G. Heldmaier. 1992. Energetics of hibernating and normothermic alpine marmots. Pp. 221-226 in B. Bassano, P. Durio, U. Gallo Orsi, and E. Macchi, eds. First International Symposium on Alpine Marmot and on genus Marmota, St. Vincent, Italy, October.

- 2000. Regulation of body temperature and energy requirements of hibernating Alpine marmots (Marmota marmota). Am J Physiol Reg Int Comp Physiol 278:R698-R704.

$\rightarrow$ Rausch R.L. and V.R. Rausch. 1971. The somatic chromosomes of some North American marmots (Sciuridae), with remarks on the relationships of Marmota broweri Hall and Gilmore. Mammalia 35:85-101.

Ruf T. and W. Arnold. 2000. Mechanisms of social thermoregulation in hibernating alpine marmots (Marmota marmota). Pp. 81-94 in G. Heldmaier and M. Klingenspor, eds. Life in the Cold. Springer, Berlin.

Schwartz O.A. and K.B. Armitage. 2002. Correlations between weather factors and life-history traits of yellow-bellied marmots. Pp. 345-351 in K.B. Armitage and V.Y. Rumiantsev, eds. Holarctic Marmots as a Factor of Biodiversity. ABF PH, Moscow.

$\rightarrow$ Schwartz O.A., K.B. Armitage, and D. Van Vuren. 1998. A 32- year demography of yellow-bellied marmots (Marmota flaviventris). J Zool 246:337-346.

Sokal R.R. and F.J. Rohlf. 1981. Biometry. 2d ed. W.H. Freeman, New York.

$\rightarrow$ Steppan S.J., M.R. Akhverdyan, E.A. Lyapunova, D.G. Fraser, N.N. Vorontsov, R.S. Hoffmann, and M.J. Braun. 1999. Molecular phylogeny of the marmots (Rodentia: Sciuridae): tests of evolutionary and biogeographic hypotheses. Syst Biol 48: 715-734.

Thompson S.E. 1979. Socioecology of the Yellow-Bellied Marmot (Marmota flaviventris) in Central Oregon. $\mathrm{PhD}$ diss. University of California, Berkeley.

Vasiliev V.N. 1992. Hibernation in black-capped marmot (Marmota camtschatica Pallas, 1811). Pp. 67-68 in B. Bassano, P. Durio, U. Gallo Orsi, and E. Macchi, eds. First International Symposium on Alpine Marmot and on genus Marmota, St. Vincent, Italy, October.

Vasiliev V.N. and N.G. Solomonov. 1996. Body temperature and metabolism in hibernating marmots (Marmota camtschatica Pallas, 1811). Pp. 265-266 in M. Le Berre, R. Ramousee, and L. Le Guelte, eds. Biodiversity in Marmots. International Marmot Network, Moscow/Lyon.

Ward J.M., Jr., and K.B. Armitage. 1981. Circannual rhythms of food consumption, body mass, and metabolism in yellowbellied marmots. Comp Biochem Physiol 69A:621-626.

Woods B.C. 2001. Diet and Hibernation of Yellow-Bellied Marmots: Why Are Marmots so Fat? PhD diss. University of Kansas, Lawrence.

Woods B.C., K.B. Armitage, and D.T. Blumstein. 2002. Yellowbellied marmots depress metabolism to enter torpor. Pp. 400-404 in K.B. Armitage and V.Y. Rumiantsev, eds. Holarctic Marmots as a Factor of Biodiversity. ABF PH, Moscow. 